\title{
Martial Guédron, De chair et de marbre. Imiter et exprimer le nu en France (1745-1815)
}

\section{Katalin Kovács}

\section{(2) OpenEdition}

1 Journals

\section{Édition électronique}

URL : https://journals.openedition.org/studifrancesi/37742

DOI : 10.4000/studifrancesi.37742

ISSN : 2427-5856

Éditeur

Rosenberg \& Sellier

\section{Édition imprimée}

Date de publication : 15 décembre 2004

Pagination : 613-614

ISSN : 0039-2944

\section{Référence électronique}

Katalin Kovács, " Martial Guédron, De chair et de marbre. Imiter et exprimer le nu en France (1745-1815) 》, Studi Francesi [En ligne], 144 (XLVIII | III) | 2004, mis en ligne le 30 novembre 2015, consulté le 08 mai 2021. URL : http://journals.openedition.org/studifrancesi/37742 ; DOI : https://doi.org/10.4000/ studifrancesi.37742

Ce document a été généré automatiquement le 8 mai 2021.

\section{(c) 9 (i) $\Theta$}

Studi Francesi è distribuita con Licenza Creative Commons Attribuzione - Non commerciale - Non opere derivate 4.0 Internazionale. 


\title{
Martial Guédron, De chair et de marbre. Imiter et exprimer le nu en France (1745-1815)
}

\author{
Katalin Kovács
}

\section{RÉFÉRENCE}

MARTIAL GUÉDRON, De chair et de marbre. Imiter et exprimer le nu en France (1745-1815), Paris, Honoré Champion, 2003 («Les Dix-huitièmes siècles»), pp. 266, ill.

1 Entre «l'imitation du marbre et celle de la chair» (p. 142), laquelle choisir? Ce choix s'imposait avec vigueur aux artistes et aux théoriciens d'art de la deuxième moitié du XVIII ème siècle. L'ouvrage de Martial Guédron se propose d'étudier l'évolution artistique en France pendant un demi-siècle: les débats théoriques dans leur rapport avec les applications pratiques lors de l'enseignement académique. La question de la représentation du corps humain et, plus spécifiquement, de la figure nue se trouve souvent au cœur de ces débats. Or, la place centrale du nu héroïque, principe hérité de la doctrine académique classique, s'explique par le fait qu'il a été tenu pour le garant de la peinture d'histoire.

2 L'étude se divise en cinq chapitres, chacun soulignant un aspect important du sujet. Dans le premier chapitre, portant sur la structure et la proportion, l'auteur rappelle que, depuis l'Antiquité, le corps de l'homme est le modèle le plus digne du peintre, et le dessin de la figure humaine le premier de tous les arts. Pourtant, le concept de corps ne comprend, pour la majorité des peintres et des théoriciens de l'époque, que le corps masculin: le corps féminin, se dérobant à l'analyse rationnelle, s'y voit négligé. Après ce rejet, le nu féminin connaît un regain d'intérêt dans l'imagerie révolutionnaire: les emblèmes et les allégories montrent des femmes robustes, incarnant des vertus civiques. 
3 L'objet des deux chapitres suivants est de définir les enjeux pédagogiques de l'enseignement académique, notamment la place de l'anatomie dans le programme d'instruction des artistes et la question du modèle. En effet, sur ces points, les opinions des artistes et des théoriciens contemporains étaient partagées entre une conception naturaliste (prêchant l'importance de l'anatomie et du modèle naturel) et une conception idéaliste (s'appuyant sur le canon antique et le respect des maîtres du passé). Tout en soulignant le rôle des principes de l'enseignement artistique moderne, dus à Léonard - la progressivité des étapes pédagogiques et l'approche morcelée du corps humain -, l'auteur passe en revue les étapes successives préparant les élèves au dessin de nu. Bien que la représentation du nu - ayant une part essentielle dans le programme d'études des artistes - ait provoqué la résistance des théoriciens progressistes, l'enseignement académique continue, même en pleine période révolutionnaire, à être dominé par les vieux principes pédagogiques.

4 L'écart entre l'interprétation orthodoxe et celle, plus libérale de la doctrine académique est particulièrement sensible dans le cas de la représentation du nu. Le troisième chapitre approche le lecteur au cœur de la question évoquée dans le titre: celle de l'imitation et de l'expression du nu. D'habitude, les théoriciens et les critiques appliquent au nu académique des critères servant traditionnellement à caractériser la peinture d'histoire: ils l'apprécient en fonction de son expressivité et continuent à voir dans l'expression une qualité susceptible de donner de la vie aux figures. Le dernier chapitre, complémentaire au précédent, développe enfin la question des passions et du caractère. Par une référence aux critiques formulées par de nombreux théoriciens d'art du XVIII İme siècle à l'égard du système de Le Brun, l'auteur trace le chemin qui conduit vers une nouvelle manière d'étudier les passions, s'appuyant sur l'observation. Or, la maîtrise du dessin de nu reste l'objectif essentiel de l'enseignement artistique: cependant, à côté du nu héroïque, prisé avant tout pour ses vertus pédagogiques, apparaît un autre type de nu masculin - le nu alangui -, signe du refus d'un idéal de perfection codifié.

5 Dans cet ouvrage - contenant une bibliographie riche, un index des noms propres et 68 illustrations -, M. Guédron réussit à replacer la question de la représentation de nu et les débats théoriques qui s'y rattachent dans une perspective essentiellement anthropologique et culturelle. Son livre, d'une lecture passionnante, apporte une vision complexe et nuancée des divers aspects du sujet. Par là même, il vise à dissiper certains préjugés: il invite le lecteur à reconsidérer le rôle de la doctrine académique tout en rappelant qu'elle était moins figée que l'on n'ait souvent tendance à le penser. 